\section{Mathematical Recreatiors}

By Prof. Maurice Kraitchik. Pp. 328. (London : George Allen and Unwin, Ltd., 1943.) 12s. 6d. net.

$\mathrm{T}$ HERE is reason to suppose that in at least some cases an interest in mathematics develops out of an interest in puzzles and problems, rather than from an interest in straightforward arithmetic. For those whose interests in mathematics have already been aroused, there are collections of mathematical recreations, of which the best known to the British reader are W. W. R. Ball's 'Mathematical Recreations and Essays" and H. E. Dudeney's "Amusements in Mathematics". Ball's book, especially as revised by H. S. M. Coxeter, lays the emphasis on the mathematics. However apparently frivolous the starting point, the reader soon finds himself guided, gently but firmly, into an approach towards important mathematical principles. Dudeney's book, on the other hand, lays the emphasis on the amusements, and appeals more to the type of person who delights in listening to the "Brains Trust".

Prof. Kraitchik's book, based on a course of lectures delivered in New York, may be regarded as a revised edition of his "La Mathématique des Jeux" (Brussels, 1930), enriched by his nine years editorship of the periodical Sphinx. His treatment is something like Ball's, but not quite so serious, and with much more attention to problems connected with games, including not only chess, "checkers" (draughts), "craps" (dice) and dominoes, but also several games very little known in England. 'The discussion of the chess rook's moves leads to an introduction to the theory of groups. There are twelve chapters : mathematics without numbers, ancient and curious problems, numerical pastimes, arithmetico-geometrical questions, the calendar, probabilities, magic squares, geometric recreations, permutational problems, the problem of the (chess) queens, the problem of the (chess) knight, and games. The longest two chapters are on numerical pastimes, which contains a good deal about the theory of numbers, and magic squares. The chapter on geometric recreations contains several interesting diagrams of mosaics.

H. T. H. P.

\section{A German Physics Reader}

By J. E. Calthrop. Pp. 83. (London and Toronto : William Heinemann, Ltd., 1943.) 7s. 6d. net.

T HE steady growth of physics places a great strain upon students and teachers of the subject and a continual look-out is kept for means of lightening the work by omissions. Unfortunately, the study of German cannot be omitted. If no more physics were published in German, it would still be necessary for many years that the physicist should at least 'muddle through' a passage in German well enough to use the German handbooks and to read research papers in bis subject. There are three minimum requirements. An elementary knowledge of the grammatical and constructional difficulties of scientific German, a basic vocabulary and a thorough knowledge of physics to make up for deficiencies in the first two.

The present volume can supply the second requirement-an excellent basic vocabulary. As the title implies, the book consists chiefly of passages in German on physics, and no help at all is given with grammar. Section 1 contains eleven extracts on the history of physics, ranging in subject from Brownian movement to radioactivity. A translation of each passage is given on the opposite page. Section 2 gives thirty passages, each with its own vocabulary. Section 3 reproduces more than thïrty science German questions from University of London examination papers. There is no collected vocabulary or index at the end of the book and the beginner would need also such a volume as Wiener's "German for the Scientist" (Bell, 1943). The price seems rather high by comparison with Wiener's book, but there is no doubt that the selection of passages - is the most comprehensive so far published for the physicist. Each extract is of interest for its content and is full of words commonly occurring in the literature. The book can be strongly recommended. W. H. G.

\section{An Introduction to Pure Solid Geometry}

By Dr. G. S. Mahajani. Second edition. Pp. xiv +104. (Poona: Aryabhushan Press, 1943.) 3 rupees.

THIS is the second edition of a book originally published in 1940. It is designed for intermediate and inter-science students at Indian universities. Its five chapters deal with lines and planes in space, the tetrahedron and parallelopiped, mensuration of prisms and cylinders, the sphere, solid angles and polyhedra. An appendix is provided in which the volume of a prismatoid is discussed. An excellent set of miscellaneous exercises then follows.

Ir order to clarify the subject and thus avoid any confusion in the mind of the student, the author has attempted to cover the essential subject-matter in the smallest number of theorems-and the attempt has been very commendably carried out. Many exercises are given which can be regarded as bookwork, and to several of these, solutions are indicated. As with the author's "Elementary Analysis", the exposition is particularly lucid and should give the student a thoroughly clear perception of the fundamental principles of solid geometry. In this new edition, the text has been rewritten and rearranged. Several new paragraphs have also been added in order to render the relevant treatment self-contained. The number of exercises, too, has been increased. The book is a model of mathematical precision and clarity, and should be very useful as well as stimulating to all students of the subject.

\section{Air-Borne Infection}

Some Observations on its Decline. By Prof. Dwight O'Hara. Pp. $x+114$. (New York : Commonwealth Fund; London: Oxford University Press, 1943.) 8s. $6 d$. net.

OHANGE in virulence of certain diseases with 1 the passage of years is a well-recognized phenomenon. Nowhere is this change so marked or, relatively, so rapid as in the diseases of the respiratory system. The last twenty-five years have seen a tremendous reduction in the mortality-rate from respiratory infections, and Prof. O'Hara has surveyed the possible explanations for this decline. He ascribes the decline to increased biological resistance rather than to any public health or therapeutic measures. Many will agree with the author in his contention that active immunity is better than passive, and that an otherwise healthy child should acquire its full immunity through having a disease such as measles rather than by being partially protected by convalescent serum. The observations on the common cold as an entity and as an abortive form of other respiratory diseases are of particular interest. The book as a whole is worthy of attention from specialist and general practitioner alike. 